\title{
A hydrodynamic model of nearshore waves and wave-induced currents
}

\author{
Ahmed Khaled Seif ${ }^{1,2}$, Masamitsu Kuroiwa ${ }^{1}$, Mazen Abualtayef $^{3}$, Hajime Mase $^{4}$, Yuhei Matsubara ${ }^{1}$ \\ ${ }^{I}$ Department of Civil Engineering, Tottori University, Koyama, Japan \\ ${ }^{2}$ National Water Research Center, Cairo, Egypt \\ ${ }^{3}$ Department of Environmental Engineering, the Islamic University of Gaza, Palestine \\ ${ }^{4}$ Disaster Prevention Research Institute, Kyoto University, Kyoto, Japan
}

\begin{abstract}
In This study develops a quasi-three dimensional numerical model of wave driven coastal currents with accounting the effects of the wave-current interaction and the surface rollers. In the wave model, the current effects on wave breaking and energy dissipation are taken into account as well as the wave diffraction effect. The surface roller associated with wave breaking was modeled based on a modification of the equations by Dally and Brown (1995) and Larson and Kraus (2002). Furthermore, the quasi-three dimensional model, which based on Navier-Stokes equations, was modified in association with the surface roller effect, and solved using frictional step method. The model was validated by data sets obtained during experiments on the Large Scale Sediment Transport Facility (LSTF) basin and the Hazaki Oceanographical Research Station (HORS). Then, a model test against detached breakwater was carried out to investigate the performance of the model around coastal structures. Finally, the model was applied to Akasaki port to verify the hydrodynamics around coastal structures. Good agreements between computations and measurements were obtained with regard to the cross-shore variation in waves and currents in nearshore and surf zone.
\end{abstract}

KEY WORDS: Quasi-3D model; Wave-current interaction; Fractional step method; Surface roller; Coastal structures; Detached breakwater; Akasaki port.

\section{INTRODUCTION}

An ability to accurately predict nearshore hydrodynamics is essential to capture the characteristics of sediment transport processes and ultimately to forecast features of coastal morphology. Waves and currents mobilize, suspend, and transport sediment cause deposition or erosion of sediment, affecting the local bottom topography.

A reliable and robust model of nearshore waves and currents is required to effectively estimate sediment transport rate and predict beach morphological evolution.

Many models for predicting nearshore wave field have been proposed. The wave energy balance equation is commonly applied for the prediction of multidirectional random wave transformation over large coastal areas.

Originally, Karlsson (1969) derived the governing equation of the phase-averaged wave model under multidirectional random waves. The non-stationary wave models WAM (WAMDI group, 1988), and SWAN (Booij et al., 1996) were based on the energy balance equation with source terms. However, diffraction was not included in these

Corresponding author: Ahmed Khaled Seif

e-mail:a_sief461@yahoo.com models, which made it difficult to apply them to coastal areas containing engineering structures. Takayama et al. (1991) also proposed a practical computation method of directional random. However, the method was not included the effect of wave diffraction.

Mase et al. (2001) introduced the diffraction term into the wave energy balance equation using a parabolic approximation. However, the experience of the writers, during this and previous modeling studies, is that predictions by the model often overestimate wave heights in the surf zone. Thus, Mase et al. (2004) introduced WABED wave model, which based on 2-D phase-averaged model that neglects changes in the wave phase in calculating wave and other nearshore processes from the wave energy density. To take the effect of ambient currents into account, the wave action density is used in WABED rather than the wave energy density since the wave action density is conservative whereas the wave energy density is not if waves travel with ambient currents. The Doppler shift is considered in the wave dispersion equation implemented in WABED to develop a practice-oriented random wave model for coastal engineering studies at inlets, navigation projects, and wave-structure interactions. 
Zheng et al. (2008) evaluated of alternative wave breaking formulas in a costal spectral wave model proposed by Mase et al. (2004). Numerical simulation results showed that with a proper breaking formulation the wave model can reproduce laboratory data for waves propagating over idealized or complicated bathymetries with ambient currents.

Although the process of wave breaking is arguably the most important phenomenon in the nearshore, much research demonstrated that the surface roller plays an important role in the generation of nearshore currents and changes in the mean water level. The dominant of the roller in dissipating energy in the surf zone is self-evident, and as noted by Svendsen (1984a), its contributions to the mean balances of mass and momentum should also significant. Consequently, the few roller models that have been developed (e.g., Svendsen, 1984b; Deigaard et al., 1991) have been tested by incorporating them in to models for the mean setup and cross-shore currents, for which data are available for comparison. Dally and Brown (1995) further developed the roller model based on a depth-integrated and period-averaged energy balance equation. The model was validated with a number of laboratory data sets. The computed results showed good agreement with the measurements. Larson and Kraus (2002) also applied this roller model in the NMLong numerical model, which was developed to simulate the longshore current across a single profile line. In almost all previous studies, the energy balance for the rollers was only taken in the cross-shore direction. Recently, Tajima and Madsen (2006) enhanced the energy balance equation in two dimensions. However, despite this improvement, it is still difficult to estimate how much broken wave energy dissipation is transferred into the surface roller, which decreases the accuracy in the calculation of the roller energy flux. In the present study, the approaches by Dally and Brown (1995) and Larson and Kraus (2002) were followed, and the energy flux term in the alongshore direction was included in the energy balance equation for the rollers.

There have been a number of numerical models for wavedriven currents around coastal structures. The nearshore current fields have been predicted by using a two dimensional depth-averaged model (2DH model), and quasi three dimensional numerical model (Q-3D model) around coastal structures (e.g. Nishimura et al., 1988; Kuroiwa et al., 2002). Zyserman and Johnson (2002) used a quasi threedimensional model, dealing with random waves, to simulate flow, sediment transport, and morphological evolution. Although the model produced reasonable-looking results of wave, current, and sediment transport, no validation was made due to lack of measurement data. In almost all previous studies, the nearshore waves and current fields were independently determined without considering the wavecurrent interaction.

The main objective of this study is to develop a reliable hydrodynamic numerical model for nearshore waves and currents around coastal regions. This article introduces a new hydrodynamic model by taking into account the wave-current interaction and the surface roller effects.

\section{NUMERICAL MODEL}

The present model consists of two modules, which are wave module and nearshore current module. The wave and nearshore current fields are dependently determined with the consideration of the wave-current interaction.

\section{Wave module}

The wave module is based on the multi-directional random wave model, which is based on the wave action balance equation associated with energy dissipation terms for the wave breaking and wave diffraction (Mase et al., 2004). In this module, the wave-current interaction was calculated. The governing wave action balance equation with the wave diffraction effects is

$$
\begin{aligned}
& \frac{\partial\left(C_{x} N\right)}{\partial x}+\frac{\partial\left(C_{y} N\right)}{\partial y}+\frac{\partial\left(C_{\theta} N\right)}{\partial \theta}= \\
& \frac{\kappa}{2 \sigma}\left\{\left(C C_{g} \cos ^{2} \theta N y\right)_{y}-\frac{1}{2} C C_{g} \cos ^{2} \theta N y y\right\}-\varepsilon_{b} N
\end{aligned}
$$

where $N$ is the wave action density, defined as the wave energy density divided by the angular frequency $\sigma$ relative to the current (Doppler shift). The horizontal coordinates are $x$ and $y$, and $\theta$ is the wave direction measured counterclockwise from the $x$-axis. As suggested by Mase et al. (2001), the default value of $k=2.5$ was used for the diffraction intensity parameter. $C$ and $C_{g}$ are the wave celerity and group velocity, respectively. The characteristic wave velocities with respect to $x, y$, and $\theta$ coordinates are accordingly $C_{x}, C_{y}$ and $C_{\theta}$ as defined by

$$
\begin{aligned}
& C_{x}=C_{g} \cos \theta+\widetilde{U} \\
& C_{y}=C_{g} \sin \theta+\widetilde{V} \\
& C_{\theta}=\frac{\sigma}{\sinh 2 k h}\left(\sin \theta \frac{\partial h}{\partial x}-\cos \theta \frac{\partial h}{\partial y}\right)+\cos \theta \sin \theta \frac{\partial \widetilde{U}}{\partial x} \\
& -\cos ^{2} \frac{\partial \widetilde{U}}{\partial y}+\sin ^{2} \theta \frac{\partial \widetilde{V}}{\partial x}-\sin \theta \cos \theta \frac{\partial \widetilde{V}}{\partial y}
\end{aligned}
$$

where $\widetilde{U}$ and $\widetilde{V}$ are the depth-averaged steady currents in the $x$ and $y$ direction, and $k$ is the wave number. The relationships between the relative angular frequency $\sigma$, the absolute angular frequency $\omega$, the wave number vector $\mathbf{k}$, the current velocity vector $\widetilde{U}$, and the water depth $h$ are shown in the following equations

$\sigma^{2}=g|\mathbf{k}| \tanh |\mathbf{k}| h$

$\sigma=\omega-\mathbf{k} \bullet \widetilde{\mathbf{U}}$ 
In Eq. (1), the parameterized function $\varepsilon_{b}$ describes the mean energy dissipation rate per unit horizontal area due to the wave breaking. The importance of this function was examined for four wave breaking formula by Zheng et al. (2008). In this study, the parameterized wave breaking function for wave energy dissipation was calculated from the following expression for bulk energy dissipation with the ambient current, which proposed by Chawla and Kirby (2002):

$$
\begin{aligned}
& \langle D\rangle=\frac{3 \lambda \rho}{32 \sqrt{\pi}} \sqrt{\frac{(g \bar{k})^{3}}{\tanh \bar{k} h}}\left(\frac{\bar{k}}{\gamma \tanh \bar{k} h}\right)^{2} \\
& \times H_{r m s}^{5}\left[1-\left\{1+\left(\frac{\bar{k} H_{r m s}}{\gamma \tanh \bar{k} h}\right)^{2}\right\}^{-5 / 2}\right]
\end{aligned}
$$

where $\langle D\rangle$ is the bulk energy dissipation by all breaking waves, $H_{r m s}$ is the root-mean-square wave height, and $\bar{k}$ is the wave number corresponding to the mean angular frequency $\bar{\sigma}$, and the scaling parameters $\lambda$ and $\gamma$ are set to 0.4 and 0.6 , respectively.

The wave breaking energy dissipation coefficient $\varepsilon_{b}$ is calculated as

$\varepsilon_{b}=\langle D\rangle /\left(0.125 \rho g H_{r m s}^{2}\right) \bar{\sigma}$

Furthermore, the energy balance equation was used in association with the surface roller term, which is based on the equation of Dally and Brown (1995) and Larson and Kraus (2002) as follows

$$
-D_{b}+\frac{\partial}{\partial x}\left(\frac{1}{2} M C_{r}^{2} \cos ^{2} \bar{\theta}\right)+\frac{\partial}{\partial y}\left(\frac{1}{2} M C_{r}^{2} \sin ^{2} \bar{\theta}\right)=-g \beta_{D} M
$$

where $D_{b}$ is the wave breaking energy dissipation, $M$ is the wave-period-averaged mass flux, $C_{r}$ is the roller speed $(\approx C)$, and the roller dissipation coefficient $\beta_{D}$ was set to 0.1 . The stresses due to the rollers are determined as follows

$$
\begin{aligned}
& R_{x x}=M C_{r} \cos ^{2} \bar{\theta} \\
& R_{y y}=M C_{r} \sin ^{2} \bar{\theta} \\
& R_{x y}=R_{y x}=M C_{r} \sin 2 \bar{\theta}
\end{aligned}
$$

\section{Nearshore current module}

The nearshore current module is based on the Q-3D nearshore current model proposed by Kuroiwa et al. (2002). Kuroiwa et al. (1998) proposed a Q-3D numerical model based on the solution method developed by Koutitas et al. (1980) and tried to calculate nearshore currents around coastal structures. However, the previous model has been only applied to the nearshore currents on the planar beach. Therefore, Kuroiwa et al. (2002) modified the previous model to be applicable to nearshore currents on a barred beach.

\section{Governing equations}

The governing equations are derived from the 3-D Navier-Stokes equations. The equations of motion for Q-3D nearshore currents may be expressed as

$$
\begin{aligned}
& \frac{\partial U}{\partial t}+U \frac{\partial U}{\partial x}+V \frac{\partial U}{\partial y}+W \frac{\partial U}{\partial z}= \\
& -g \frac{\partial \bar{\zeta}}{\partial x}-\frac{\partial\left(S_{x x}+R_{x x}\right)}{\partial x}-\frac{\partial\left(S_{x y}+R_{x y}\right)}{\partial y} \\
& +\frac{\partial}{\partial x}\left(v_{h} \frac{\partial U}{\partial x}\right)+\frac{\partial}{\partial y}\left(v_{h} \frac{\partial U}{\partial y}\right)+\frac{\partial}{\partial z}\left(v_{v} \frac{\partial U}{\partial z}\right)
\end{aligned}
$$

$\frac{\partial V}{\partial t}+U \frac{\partial V}{\partial x}+V \frac{\partial V}{\partial y}+W \frac{\partial V}{\partial z}=$

$-g \frac{\partial \bar{\zeta}}{\partial y}-\frac{\partial\left(S_{y x}+R_{y x}\right)}{\partial x}-\frac{\partial\left(S_{y y}+R_{y y}\right)}{\partial y}$

$+\frac{\partial}{\partial x}\left(v_{h} \frac{\partial V}{\partial x}\right)+\frac{\partial}{\partial y}\left(v_{h} \frac{\partial V}{\partial y}\right)+\frac{\partial}{\partial z}\left(v_{v} \frac{\partial V}{\partial z}\right)$

where $U, V$ and $W$ are the steady current velocities in the $x, y$ and $z$ directions. $S_{x x}, S_{y y}, S x y$, and $S_{y x}$ represent the terms of excess momentum fluxes due to the waves. $v_{v}$ and $v_{h}$ represents the turbulent eddy viscosity coefficient in the vertical and horizontal directions, respectively. $v_{v}$ is estimated by Tsuchiya et al. (1986):

$v_{v}=A_{v} C H_{r m s}$

where $A_{v}$ is a dimensionless coefficient set at 0.005 , and $v_{h}$ is estimated by Larson et al. (2002):

$v_{h}=\Lambda \hat{u}_{w} H_{r m s}$

where $\Lambda$ is a constant value set at $1.50, \hat{u}_{w}$ is the maximum water particle velocity in the $x$ direction.

The radiation stress part was modified by adding the momentum fluxes term due to the surface roller as $R_{x x}, R_{y y}$, $R_{x y}$, and $R_{y x}$. The continuity equation is expressed as

$\frac{\partial U}{\partial x}+\frac{\partial V}{\partial y}+\frac{\partial W}{\partial z}=0$

The depth-integrated continuity equation is

$\frac{\partial \bar{\zeta}}{\partial}+\frac{\partial \widetilde{U}(h+\bar{\zeta})}{\partial x}+\frac{\partial \widetilde{V}(h+\bar{\zeta})}{\partial y}=0$

where $\widetilde{U}$ and $\widetilde{V}$ are the depth-averaged steady currents, and $\bar{\zeta}$ is the mean water level. 


\section{Boundary conditions}

The shoreline is treated as a fixed boundary of the computational domain. The seaward boundary is also regarded as fixed by locating it in deep water where there is no current. Therefore, current velocity components normal to these boundaries are taken as zero. Both the alongshore current velocity and the water level are uniform alongshore at the lateral boundaries.

The boundary conditions at the sea bottom are given as;

$\left.v_{v} \frac{\partial U}{\partial z}\right|_{z=-h}=\frac{1}{\rho} \tau_{b x} \quad,\left.\quad v_{v} \frac{\partial V}{\partial z}\right|_{z=-h}=\frac{1}{\rho} \tau_{b y}$

where $\tau_{b x}$ and $\tau_{b y}$ are the shear stresses caused by bottom friction and include the effects of interaction between the steady current and wave oscillatory motion.

The boundary condition at the mean water level are given as

$\left.v_{v} \frac{\partial U}{\partial z}\right|_{z=\bar{\zeta}}=\frac{1}{\rho} \tau_{s x} \quad,\left.\quad v_{v} \frac{\partial V}{\partial z}\right|_{z=\bar{\zeta}}=\frac{1}{\rho} \tau_{s y}$

where $\tau_{s x}$ and $\tau_{s y}$ are the shear stress in $x$ and $y$ direction given as

$$
\left\{\begin{array}{l}
\rho v_{v} \frac{\partial U}{\partial z}=\tau_{s x}=A_{s} \rho^{1 / 3} D_{b}^{2 / 3}\left(h / L_{p}\right) \cos \theta \\
\rho v_{v} \frac{\partial V}{\partial z}=\tau_{s y}=A_{s} \rho^{1 / 3} D_{b}^{2 / 3}\left(h / L_{p}\right) \sin \theta
\end{array}\right.
$$

where $\rho$ is the density of seawater, $h$ is the water depth, $L_{p}$ is the wave length with peak frequency, $A_{s}$ is dimensionless coefficient, $D_{b}$ is the energy dissipation rate given as

$D_{b}=\frac{K_{c}}{h} C_{g} \frac{1}{8} \rho g\left\{H_{r m s}{ }^{2}-\left(\Gamma_{c} h\right)^{2}\right\}$

where $K_{c}$ and $\Gamma_{c}$ are dimensionless coefficients.

\section{Numerical schemes}

The governing equations were solved using the fractional step method, originally suggested by Koutitas and O'Connor (1980). This method combines the finite difference method in the horizontal plane, and the Galerkin finite element method (FEM) in the vertical direction. This hybrid method was used to solve the equation of motion by dividing it into two differential sections and integrating separately for the two stages. Because the FEM was used in the vertical direction, the water depth could be divided into equal layer thicknesses, and near the sea-bottom layer, a fine division was possible. In this computation, the position of variables was defined using a space-staggered grid system.

An iterative feed back process between the wave module and the nearshore current module was carried out to obtain the steady state condition, as shown in Fig. 1. In order to reach the steady state condition, the wave field calculation was updated by taking the average wave field between the previous and present iteration to compute the nearshore current field for the next iteration.

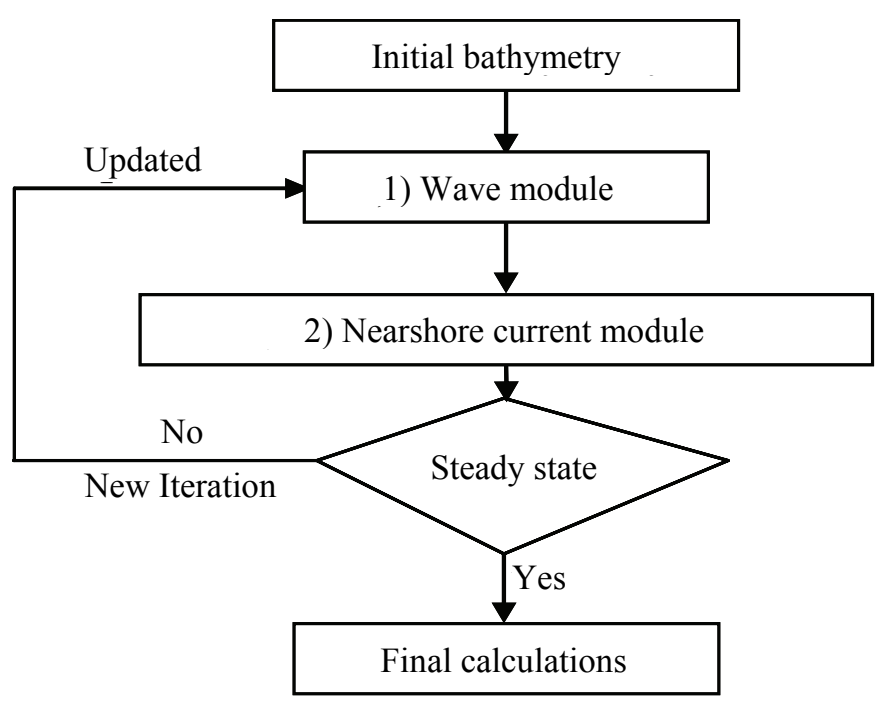

Fig. 1 Flowchart of the numerical model.

\section{MODEL TESTS}

\section{LSTF Experimental Model Test}

Firstly, the present model was applied to the longshore current experimental model under an irregular wave from the Large Scale Sediment Transport Facility (LSTF), performed by Hamilton and Ebersole et al. (2001), in order to validate the model.

\section{LSTF model setup}

The computation was performed in a concrete beach with alongshore dimension of $31 \mathrm{~m}$ and a cross-shore dimension of $21 \mathrm{~m}$, and the plane slope was 1:30. The grid size was $\Delta x=\Delta y=0.5 \mathrm{~m}$. The significant wave height at the offshore boundary was $0.225 \mathrm{~m}$, the significant wave period was $2.5 \mathrm{~s}$, and the wave direction at the wave generations was 10 degree. In Eq.7, $\lambda$ was set to 1.8 in order to calibrate the nearshore current field.

\section{LSTF model results}

The computed results of our model were compared with the experimental model results. Figs. 2(a) and (b) show comparisons between the computed and measured wave height distribution, and longeshore current, with and without the wave-current interaction and the surface roller effect. The model was run until the steady state with the consideration of wave-current interaction was reached. The prediction of significant wave height was in a good agreement with the measurements when the wave-current interaction was considered, as shown in Fig. 2(a). The computed results of 
longeshore currents with the effect of the surface roller was not only shifted the peak toward the shoreline, but also increased the maximum current magnitudes in the surf zone, as shown in Fig. 2(b). From these results, it was found that the computed wave height distribution and longeshore current were in a good agreement with the experimental results.

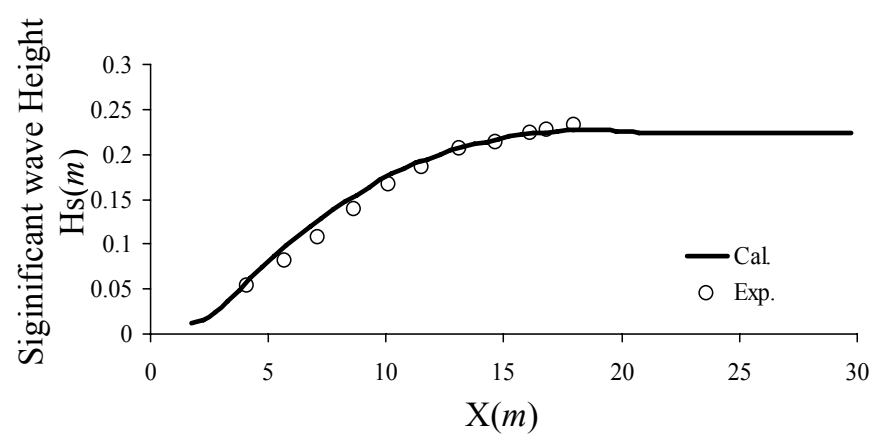

Fig. 2(a) Computed and observed wave height distribution.

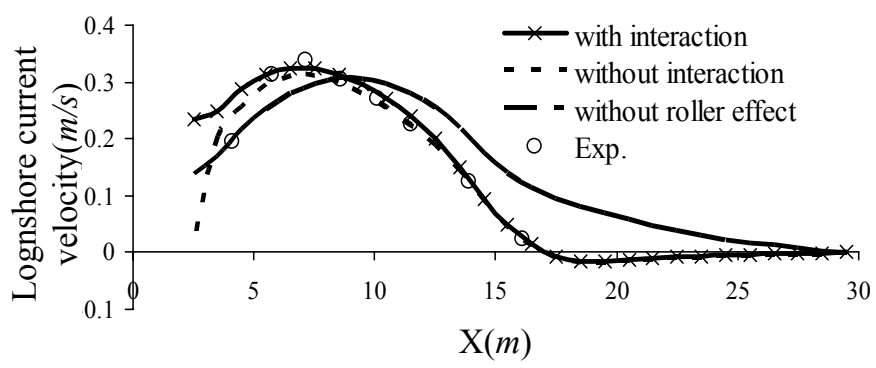

Fig. 2(b) Computed and observed longshore current velocities.

\section{HORS Model Test}

Secondly, the results of field observations conducted by Kuriyama et al. (1999) were used in this study to calibrate and verify the model. The field observations of the wave heights, the cross-shore and longshore current velocities were carried out from January 29 to February 3, 1997 at the Hazaki Oceanographical Research Station (HORS) of the Port and Airport Research Institute. Fig. 3 show the sea-bottom topography measured on January 31, and the current measurement points.

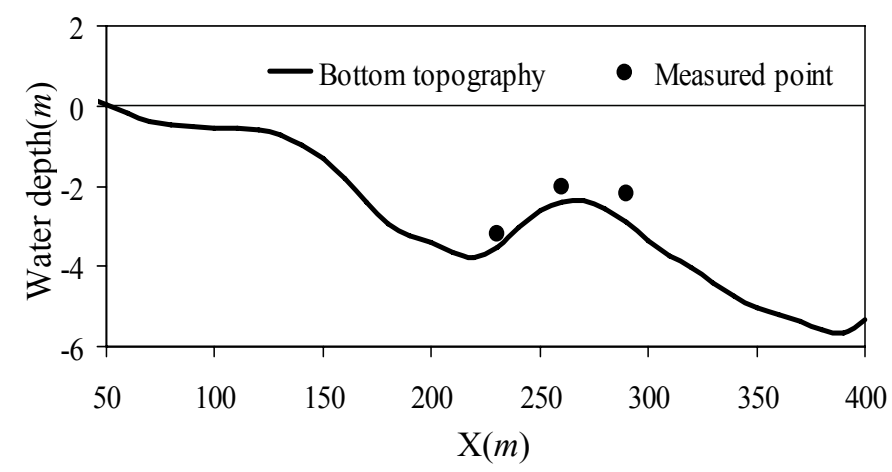

Fig. 3 The sea-bottom topography and current measuring locations.

\section{HORS model setup}

The computations were performed on an area of $0.2 \mathrm{~km}$ alongshore and $0.4 \mathrm{~km}$ cross-shore. The grid size was $\Delta x=\Delta y=10 \mathrm{~m}$. Four of the fourteen wave conditions reported by Kuriyama et al., (1999) were used to calibrate and verify the model. The wave data input at the offshore boundary are shown in Table 1.

Table 1 Wave data input at the offshore boundary.

\begin{tabular}{|c|c|c|c|c|}
\hline Case & $d, m$ & $H_{1 / 3}, m$ & $T_{I / 3}, s$ & $\theta, d e g$ \\
\hline Case 1 & 6.70 & 2.00 & 9.69 & 24.50 \\
\hline Case 2 & 6.58 & 2.11 & 9.63 & 16.50 \\
\hline Case4 & 6.98 & 2.91 & 11.81 & 19.00 \\
\hline Case7 & 6.65 & 2.37 & 12.16 & 6.00 \\
\hline
\end{tabular}

\section{HORS model results}

Figs. 4 7 show comparisons between the computed results and measured data of the significant wave heights, the cross-shore and longshore current velocities. These comparisons show that the computed results of wave heights give a good agreement with the measured data. The computed cross-shore current velocities also give reasonable agreement with the measured data. The computed cross-shore currents for Case 4 is the most accurate predictions of the measured data. The computed longshore current velocities for Cases 1, 2 and 4 also give reasonable agreements with the measured data. The computed results for Case 7 underestimated the measured data. It is thought that the computed results in Case 7 are lower because the deep-water wave angle is less than in the other cases. Hence, the longshore current velocities computed by the present model are dependent on the wave angle. The computed longshore currents for Case 1 is the most accurate predictions of the measured data. It is found that the computed result give a good agreement with the measured data.

\section{Detached Breakwater Model Test}

A model test associated with detached breakwater with and without the wave-current interaction was carried out to investigate the performance of the model around coastal structures.

\section{Numerical model setup}

The computation was performed on an area of $0.6 \mathrm{~km}$ alongshore and $0.6 \mathrm{~km}$ cross-shore. The initial bathymetry with a gradient of 1:50 was set. The grid size was $10 \mathrm{~m}$ $(\Delta x=\Delta y)$. The significant wave height at the offshore boundary was $1.5 \mathrm{~m}$, and the significant wave period was $7.0 \mathrm{~s}$. The length of the breakwater was equal to $210 \mathrm{~m}$, and the distance to the initial shoreline was equal to $150 \mathrm{~m}$. 

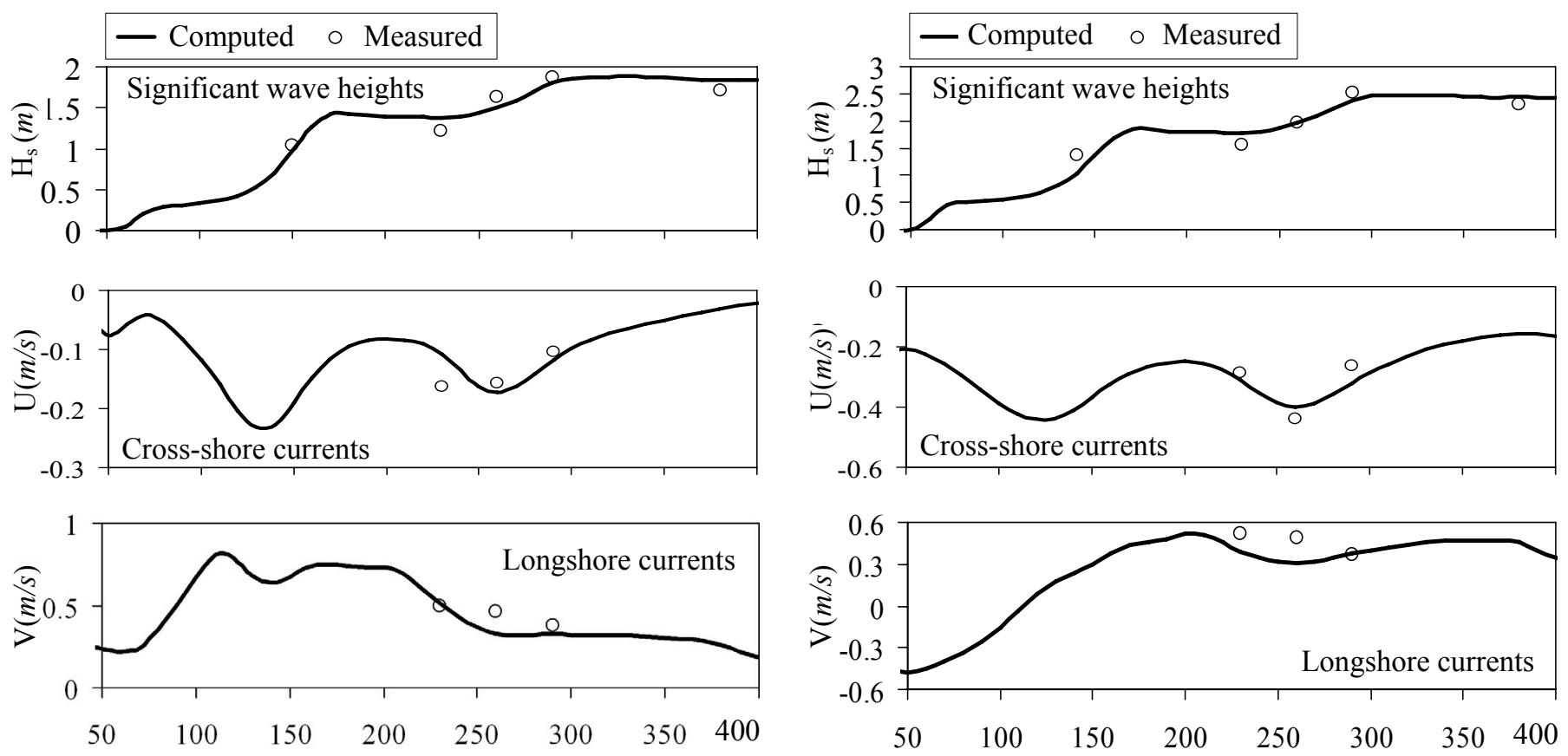

Fig. 4 Computed and measured wave height, cross-shore currents, and longshore current for Case. 1.

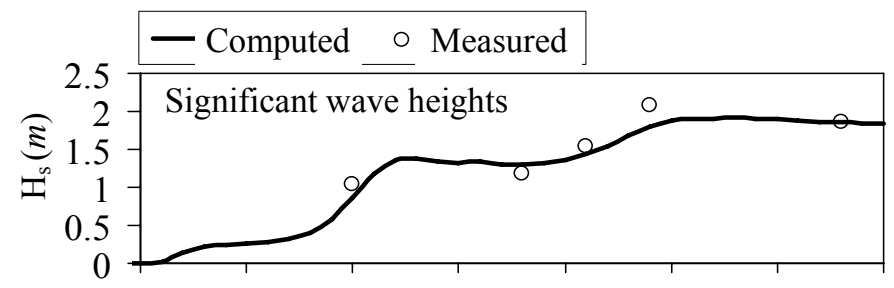

Fig. 6 Computed and measured wave height, cross-shore currents, and longshore current for Case. 4.
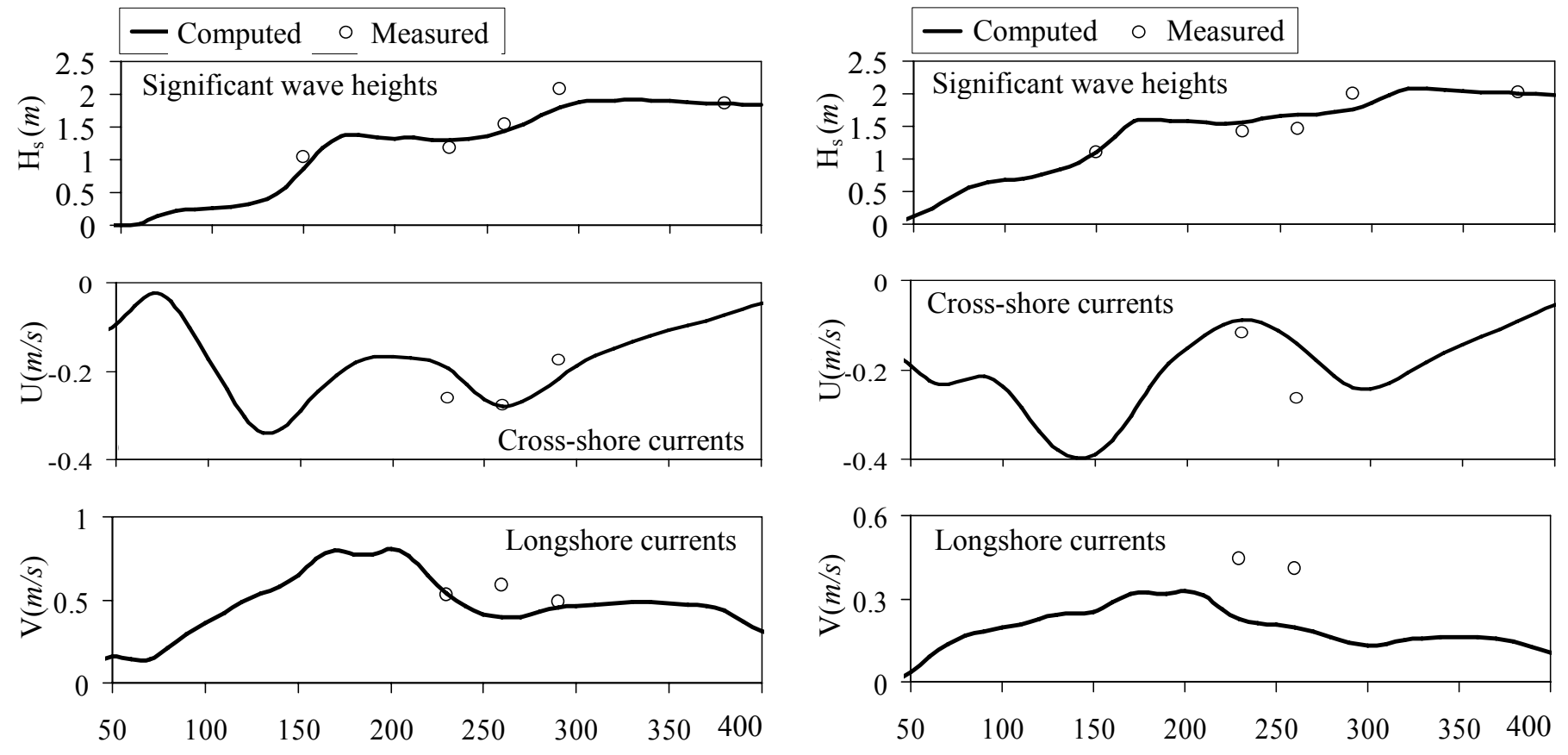

Fig. 5 Computed and measured wave height, cross-shore currents, and longshore current for Case. 2.

\section{Numerical model results}

Figs. 8 9 show the computed results of wave height distribution and bottom current velocity around the detached breakwater, without and with the wave-current interaction, respectively. From these figures, it was found that by considering the wave-current interaction, the wave height distribution behind the detached breakwater, and the

Fig. 7 Computed and measured wave height, cross-shore currents, and longshore current for Case. 7.

magnitude of the current velocities were changed. This is due to the model run reached the steady state condition only when the wave-current interaction was considered.

As a conclusion of the model tests, it was found that the wave-current interaction was significantly playing an important role in the prediction of the hydrodynamic computation around the coastal structures. 

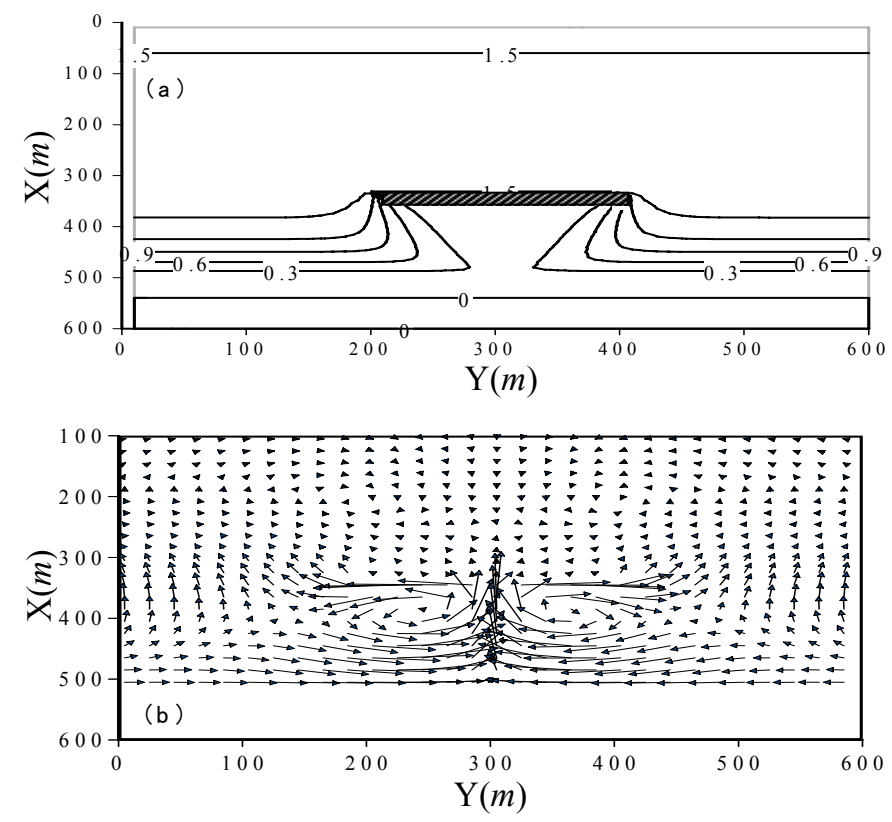

Fig. 8 Computed (a) wave height distribution and (b) bottom current velocity without interaction.
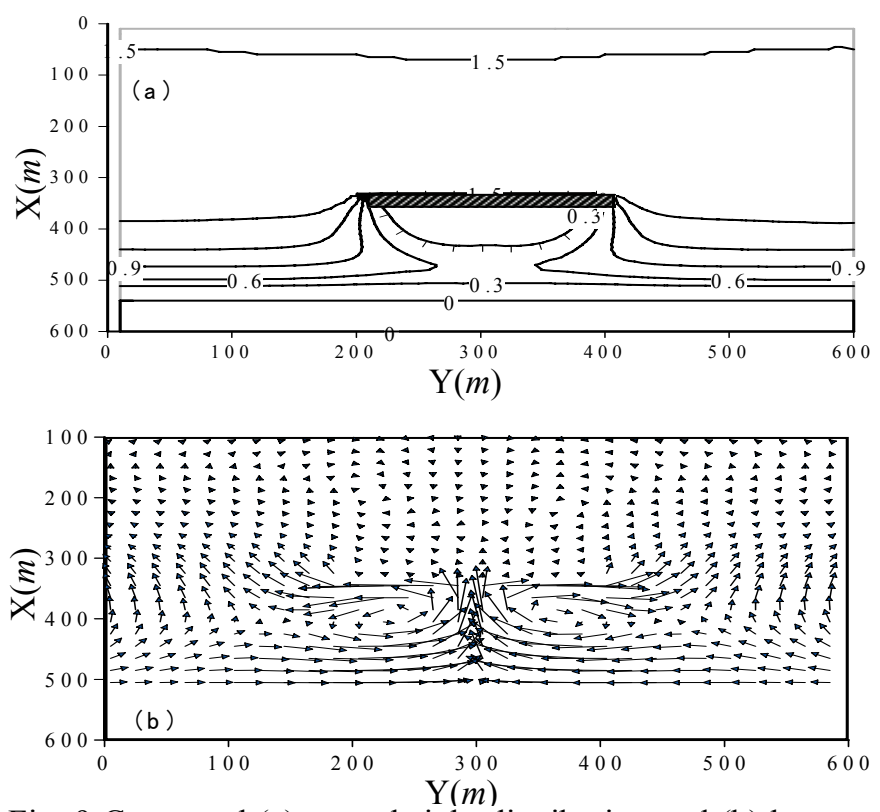

Fig. 9 Computed (a) wave height distribution and (b) bottom current velocity with interaction.

\section{MODEL VERIFICATION}

Finally, the present model was applied to the prediction of the nearshore current field around Akasaki port, Tottori, Japan. The field measurements were carried out from December 1996 to March 1997 (Kuroiwa et al. 2000). Fig. 10 shows the bottom topography around Akasaki port and the stations measuring the wave heights and current velocities data. The measured wave data at the measuring stations are shown in Table 2.

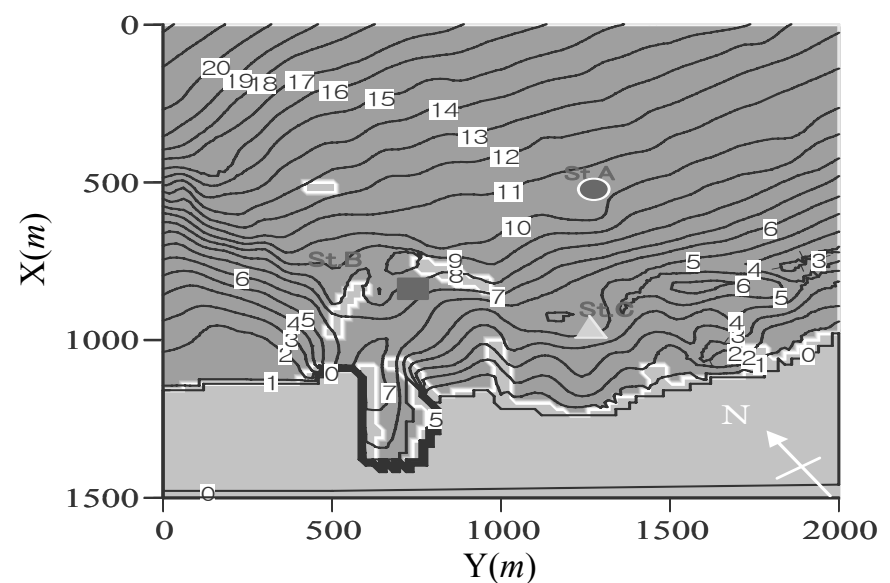

Fig. 10 Bottom topography around Akasaki port and the measuring stations of wave and current data.

Table 2 Measured wave data at the measuring stations.

\begin{tabular}{|c|c|c|c|c|}
\hline \multicolumn{2}{|c|}{ Wave conditions } & St.A & St.B & St.C \\
\hline \multirow{2}{*}{ Case 1} & $H_{1 / 3}, m$ & 2.73 & 1.35 & 2.09 \\
\cline { 2 - 5 } NNW & $T_{l / 3}, s$ & 8.5 & 8.1 & 8.8 \\
\cline { 2 - 5 } & $\theta, d e g$ & -26 & -10 & -12 \\
\hline \multirow{2}{*}{ Case 2} & $H_{l / 3}, m$ & 3.92 & 2.00 & 3.26 \\
\cline { 2 - 5 } NNE & $T_{l / 3}, s$ & 8.6 & 9.2 & 8.9 \\
\cline { 2 - 5 } & $\theta, d e g$ & 26 & 7 & 18 \\
\hline
\end{tabular}

\section{Model setup}

The computation was performed in an area of $2.0 \mathrm{~km}$ in the alongshore direction and $1.5 \mathrm{~km}$ in the cross-shore direction. The initial bathymetry with the gradient of 1:50 was set. The grid size was $20 \mathrm{~m}$. To verify the model, two typical stormy wave cases in the winter season were used. The stormy wave conditions at the offshore boundary are shown in Table 3 .

Table 3 Wave data input at the offshore boundary.

\begin{tabular}{|c|c|c|c|}
\hline Case & $H_{l / 3}, m$ & $T_{l / 3}, s$ & $\theta$, deg \\
\hline NNW & 2.85 & 8.7 & -40 \\
\hline NNE & 3.65 & 8.7 & 20 \\
\hline
\end{tabular}

\section{Model results}

The significant wave height distributions for Case NNW and NNE are shown in Figs. 11 12. Figs. 13 14 show the comparison of the significant wave heights and mean wave directions at the measuring stations $\mathrm{A}, \mathrm{B}$ and $\mathrm{C}$. Although the computed wave height and direction at station B (St.B) in case NNE are different from the measured data, the modified wave model gives a reasonable prediction for station A (St.A), and good agreement with station C (St.C). Figs. 15 16 show comparisons between the computed and measured results of the current fields near the sea bottom. From these comparisons, it was found that the present model satisfactorily predicts the current field, except at station A (St.A). A possible cause of the discrepancy at St.A may be due to that the present model cannot take into account the wind-induced currents. As future work, the interaction between the wind- and wave-induced currents will be considered. 


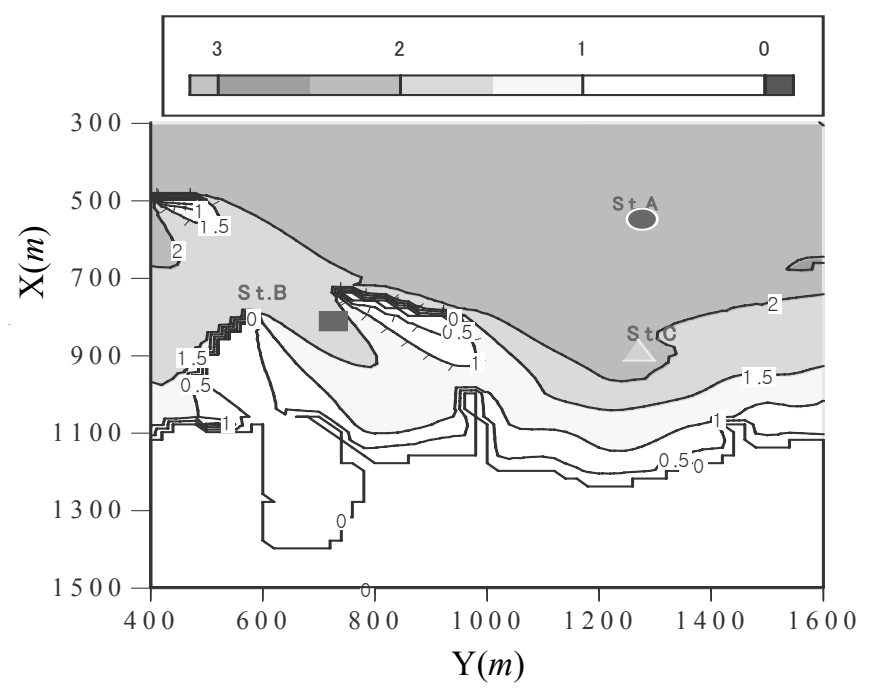

Fig. 11 Computed wave height distribution around Akasaki port for Case NNW.

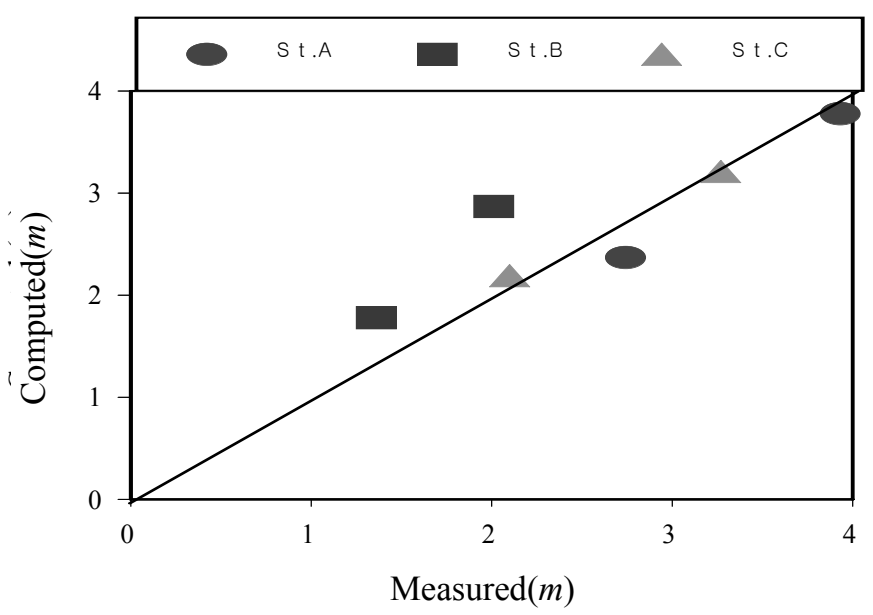

Fig. 13 Comparison between the measured and computed wave height.

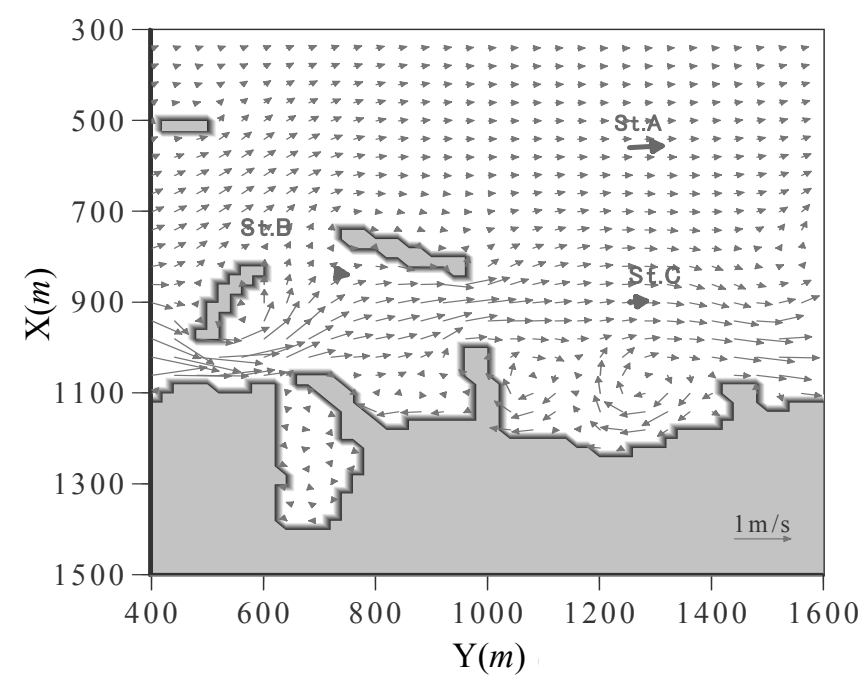

Fig. 15 Comparison between the measured and computed current vectors near sea bottom for Case NNW.

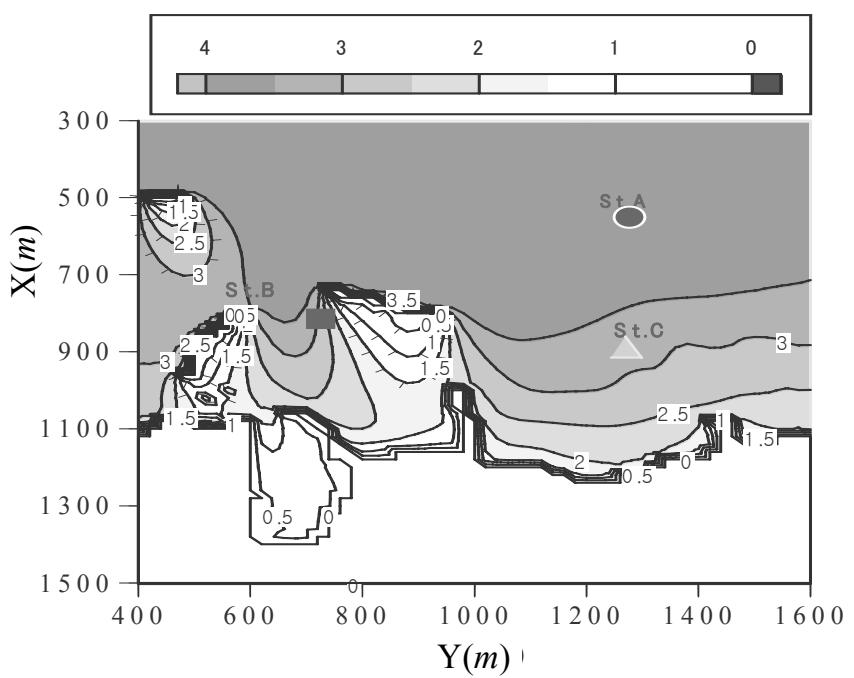

Fig. 12 Computed wave height distribution around Akasaki port for Case NNE.

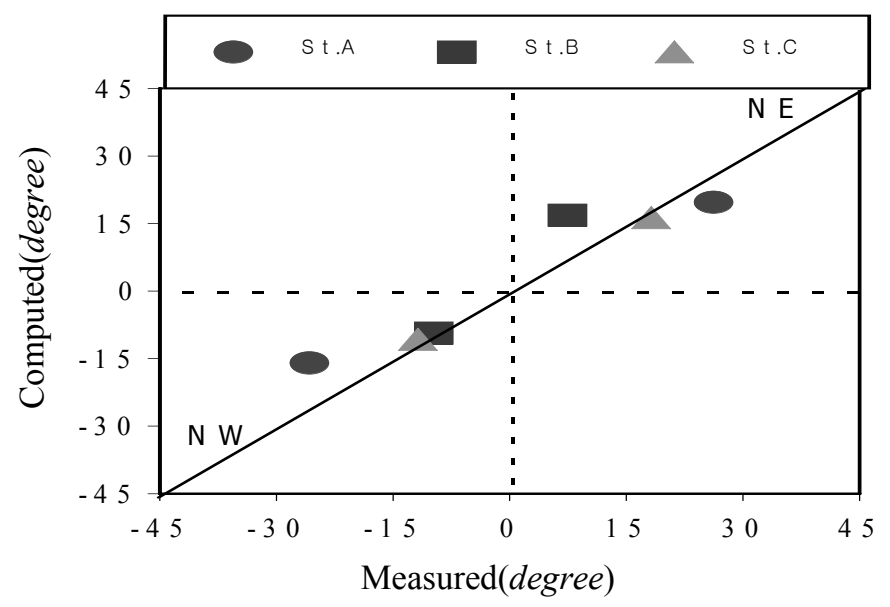

Fig. 14 Comparison between the measured and computed wave direction.

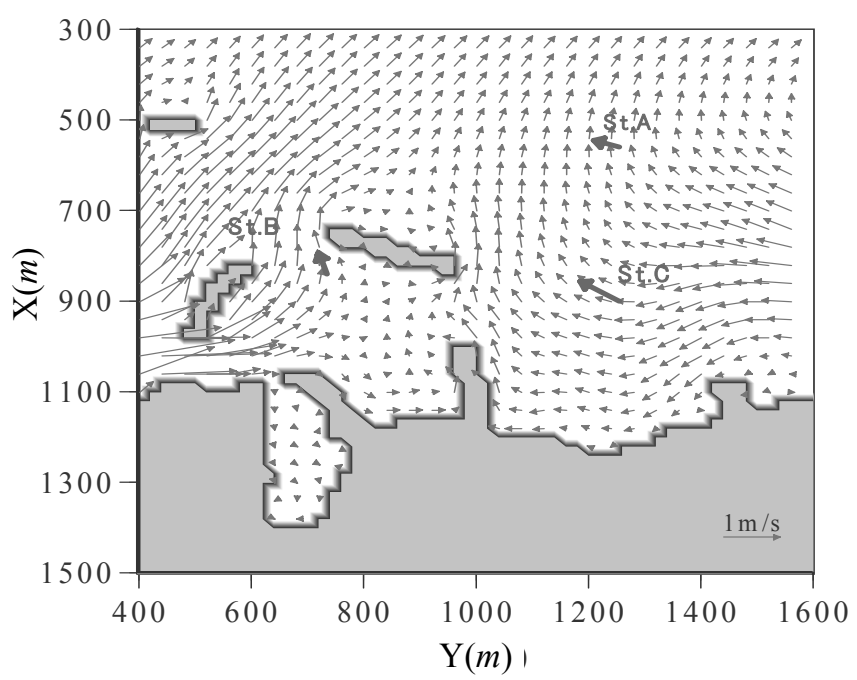

Fig. 16 Comparison between the measured and computed current vectors near sea bottom for Case NNE. 


\section{CONCLUSIONS}

In this article, the hydrodynamic model of wave driven coastal currents with accounting the effects of the wavecurrent interaction and the surface rollers around coastal structures was developed. The applicability of the model was demonstrated through several numerical tests and compared with a laboratory experiment and field observations. The new proposed hydrodynamic model shows good agreement with the observations. Furthermore, it was found that the wavecurrent interaction with the surface roller was significantly playing an important role for the prediction of the hydrodynamic computations.

\section{REFERENCES}

Booij, N. Holthuijsen, L.H. and Ris, R.C., 1996. The SWAN' wave model for shallow water. Proc., 25th Int. Conf. on Coastal Engineering, ASCE, pp.668-676.

Chawla, A. and Kirby, J.T., 2002. Monochromatic and random wave breaking at blocking points. Journal of Geophysical Research, 107(C7), pp.4,1-4,19.

Dally, W.R. and Brown, Ch.A., 1995. A modeling investigation of the breaking wave roller with application to cross-shore currents. Journal of Geophysical Research, 100(C12), pp.873-883.

Deigaard, R. Justesen, P. and Fredsoe, J. 1991. Modeling of undertow by a one-equation turbulence model, Coastal Eng., 15, pp.431-458.

Hamilton, D.G. and Ebersole, B.A., 2001. Establishing uniform longeshore currents in a large-scale sediment transport facility. Coastal Eng, 42, pp.199-218.

Karlsson, T., 1969. Refraction of continuose ocean wave spectra, Proc. ASCE, 95(WW4), pp.471-490.

Koutitas, C. O’Connor, B., 1980. Modeling 3D wind-induced flows. Journal of Hydraulic Division, ASCE, 11, pp. 1843-1865.

Kuriyama, Y. and Nakatsukasa. T., 1999. Undertow and Longshore current on a Bar-Trough Beach, Field Measurements at HORS and Modeling-, Rep. Port and Harbor Res. Inst., 38(1).pp.3-28.

Kuroiwa, M. Noda, H. and Matsubara, Y., 1998. Applicability of a quasi-three dimensional numerical model to nearshore currents, 26th, Proc. of Int. Conf. on Coastal Eng., pp.815-828.
Kuroiwa, M. Noda, H. Son, C.B. Kato, K. and Taniguchi, S., 2000. Numerical prediction of bottom topographical change around coastal structures using quasi-3D nearshore current model. Proc. of the 27th ICCE, pp.2914-2927.

Kuroiwa, M. Matsubara, Y. Kuchiishi, T. Kato, K. Noda, H. and Son, C.B.A., 2002. Morphodynamic model based on Q-3D nearshore current model and application to barred beach. 28th ICCE, pp.3409-3421.

Larson, M. and Kraus, N.C.NMLONG., 2002. Numerical model for simulating longshore current. Coastal and Hydraulics Laboratory Technical Report ERDC/CHL TR-02-22. Vicksburg, MS: U.S. Army Engineer Research Center.

Mase, H., 2001. Multi-directional random wave transformation model based on energy balance equation. Coastal Eng J., 43(4), pp.317-337.

Mase, H. Yuhi, M. Amamori, H. and Takayama, T., 2004. Phase Averaging wave prediction model with breaking and diffraction effects in wave-current coexisting field. Annual Journal of Coastal Engineering, JSCE., 51(1), pp.6-10 (in Japanese).

Nishimura, H., 1988. Computation of nearshore current, nearshore dynamics and coastal process -Theory, Measurements and Predictive Models, University of Tokyo Press, pp.271-291.

Svendsen, I. A., 1984a. Mass flux and undertow in a surf zone. Coastal Eng., 8, pp.347-365.

Svendsen, I. A., 1984b. Wave heights and set-up in a surf zone. Coastal Eng., 8, pp.303-329.

Tajima, Y. and Madsen, O.S., 2006. Modeling near-shore waves, surface rollers, and undertow velocity profiles. J. Waterway, Port, Coastal, Ocean Eng., 132(6), pp.429-438.

Takayama, T. Ikeda, N. and Hiraishi, T., 1991. Practical Computation Method of Directional Random Wave Transformation, Report of the port and harbor institute, Ministry of Transport, 30(1), pp.21-68.

Tsuchiya, Y. Yamashita, T. and Uemoto, M., 1986. A model of undertow in the surf zone. Proceedings of the 33rd Japanese Conference on Coastal Engineering, JSCE, pp.31-35.

WAMDI Group., 1988. The WAM model-a third generation ocean wave prediction model, J. Phys. Oceanogr., 18, pp.1775-1810.

Zheng, J. Mase, H. Demirbilek, Z. and Lin, Li., 2008. Implementation and evaluation of alternative wave breaking formula in a costal spectral wave model. Ocean Eng, 35, pp.1090-1101.

Zyserman, J.A. and Johnson, H.K., 2002. Modeling morphological processes in the vicinity of shore-parallel breakwaters, Coastal Eng., 45, pp.261-284. 